\title{
Post-traumatic stress disorder in serious accidental injury: 3-year follow-up study
}

Urs Hepp, Hanspeter Moergeli, Stefan Buchi, Helke Bruchhaus-Steinert, Bernd Kraemer, Tom Sensky and Ulrich Schnyder

\section{Background}

Long-term data on post-traumatic stress disorder (PTSD) following accidents are scarce.

\section{Aims}

To assess and predict PTSD in people 3 years after severe accidental injury.

\section{Method}

Severely injured patients were recruited consecutively from the intensive care unit $(n=121)$ and assessed within 1 month of the trauma. Follow-up interviews were conducted 6 months, 12 months and 36 months later; 90 patients participated in all four interviews. Symptoms were assessed using the Clinician-Administered PTSD Scale.

\section{Results}

Post-traumatic stress disorder was diagnosed in $6 \%$ of patients 2 weeks after the accident, in 2\% after 1 year and in $4 \%$ after 3 years. Robust predictors of later PTSD symptom level were intrusive symptoms shortly after the accident and biographical risk factors. There were individual changes over time between the categories PTSD, sub-threshold PTSD and no PTSD. Whereas PTSD symptom severity was low or decreased for most of the patients, some of them showed an increase or a delayed onset. Patients with persisting PTSD symptoms at 6 months and patients with delayed onset of symptoms are at risk of long-term PTSD.

\section{Conclusions}

The prevalence of PTSD was low over the whole period of 3 years.

\section{Declaration of interest}

None. Funding detailed in Acknowledgements.
Following the introduction of the diagnosis post-traumatic stress disorder (PTSD) in 1980, ${ }^{1}$ research has focused mainly on populations at risk such as combat veterans, ${ }^{2,3}$ victims of natural disasters, ${ }^{4}$ and victims of criminal and sexual assault. ${ }^{5,6}$ As a consequence of the changes in the stressor criterion in DSM-IV, ${ }^{7}$ research on PTSD was extended to a broader spectrum of traumatic events and increasing attention was directed to physical injuries due to accidents. ${ }^{8-11}$ Although PTSD has been recognised as a severe and often chronic disorder following traumatic events, ${ }^{12}$ data on long-term outcome in the aftermath of accidents are scarce. ${ }^{13-15}$ Rates of PTSD 3-5 years post-accident vary between $1 \%$ and $11 \%^{13-15}$ and many of the patients not meeting the diagnostic criteria for PTSD experienced anxiety, hyperarousal or avoidance. There is evidence that the level of impairment in social and work functioning in people with sub-threshold PTSD is comparable with that of people with the full condition. ${ }^{16} \mathrm{Malt}^{13}$ used a clinical interview and the Impact of Event Scale (IES), ${ }^{17}$ whereas in the other studies participants filled in self-rating questionnaires. ${ }^{14,15}$ No long-term study used a structured clinical diagnostic interview to assess PTSD. The aim of our study was, therefore, to determine the prevalence of PTSD and sub-threshold PTSD 3 years post-accident and to identify long-term predictors of PTSD in a sample of severely injured accident survivors, using the Clinician-Administered PTSD Scale (CAPS) ${ }^{18}$ Additionally, we aimed to describe changes in PTSD severity and identify different courses of PTSD symptoms, and to study associations with comorbid symptoms of anxiety and depression over time.

\section{Method}

\section{Participants}

Participants were recruited from the Department of Traumatology at Zurich University Hospital. The study sample was enrolled between January 1996 and June 2000. All patients qualifying for the study had sustained accidental injuries that caused a lifethreatening or critical condition requiring their referral to the intensive care unit. Participants had to meet the following criteria to be included in the study: age 18-70 years; sufficient proficiency in the German language to participate in the interview and fill in the questionnaires; and clinical condition allowing participation in an extensive clinical interview within 1 month of the accident. Furthermore, an Injury Severity Score (ISS) of 10 or more and a Glasgow Coma Scale (GCS) score of 9 or more were required, ${ }^{19,20}$ which allowed us to collect a sample of participants who were severely injured but free from severe traumatic brain injury. Patients were excluded if they had any serious somatic illness; had been under treatment for any mental disorder immediately prior to the accident; had shown marked clinical signs or symptoms of mental disorders that were obviously unrelated to the accident; had been referred owing to attempted suicide; or were victims of violent assault.

All patients referred to the intensive care unit were consecutively screened over a period of 18 months. Sixteen patients were excluded owing to the presence of pre-existing psychiatric morbidity. In total, 135 patients were eligible for the study, of whom 14 refused to participate. Written informed consent was thus obtained from 121 patients. The initial interview was performed an average of 13 days (s.d.=7, range 3-29) after the accident $\left(T_{1}\right)$. Follow-up interviews were conducted 6 months $\left(T_{2}\right), 12$ months $\left(T_{3}\right)$ and 36 months $\left(T_{4}\right)$ after the patient's accident. A total of 90 patients participated in all four interviews.

\section{Measures}

Symptoms of post-traumatic stress were assessed using the IES and CAPS. ${ }^{17,18}$ The IES is a 15 -item self-rating questionnaire comprising two sub-scales (Intrusion and Avoidance). Cronbach's $\alpha$ was 0.89 for the IES. The CAPS interview assesses 17 specific symptoms of PTSD and allows quantification of the frequency 
and intensity of each of these symptoms according to DSM-III-R. ${ }^{21}$ The CAPS assessment was conducted by clinically experienced medical doctors. Patients were diagnosed with 'sub-threshold' PTSD if they met criteria A (stressor criterion) and B (re-experiencing cluster) plus either C (avoidance cluster) or D (hyperarousal cluster), but not C and D. ${ }^{8,22}$ The CAPS has excellent psychometric properties; ${ }^{23}$ Cronbach's $\alpha$ was 0.71 . Because patients with retrograde amnesia scored extremely high on item 7 (psychogenic amnesia) of this scale, and being unable to differentiate organic from psychogenic amnesia, we decided to omit item 7 in all further calculations. This procedure resulted in an increase in Cronbach's $\alpha$ from 0.71 to 0.77 . Our German translation of the CAPS version adapted for DSM-IV was validated. ${ }^{7}$ The internal consistency of the German version was 0.88 and the CAPS scores correlated with the validated German version of the IES $(r=0.56) .^{24}$

The Symptom Checklist-90-Revised (SCL-90-R) was used to assess a broad spectrum of psychological complaints. ${ }^{25,26}$ For group comparisons, the Global Severity Index of the SCL-90-R was used $(\alpha=0.96)$.

Patients' social networks and recent life events were assessed using a questionnaire compiled from a revised version of the Social Network Index ${ }^{27}$ an adapted version of the Social Support Questionnaire, ${ }^{28}$ and the Inventory for Determining Life-changing Events. ${ }^{29}$ Biographical protective and risk factors for the development of psychological and psychosomatic disorders were determined in a semi-structured interview based on a compilation of scientifically established factors. ${ }^{30}$ Childhood biographical risk factors are as follows: low socio-economic and educational status of the parents; professional occupation of the mother in the first year; families with many children; contact with social services; delinquency and dissocial behaviour of one parent; chronic marital problems of parents; uncertain attachment in early childhood; severe physical disease of one parent; psychiatric disorders of parents; single parent; loss of the mother; authoritarian behaviour of the father; frequently changing relationships in childhood; childhood sexual abuse; poor integration within peers; age difference between siblings less than 18 months; born to an unmarried mother. Biographical protective factors are: stable attachment to at least one primary person; multigeneration familial support; higher than average intelligence; outgoing temperament; firm attachment behaviour; reliable relationships in adulthood; stable partnerships. Each item could be scored as present (1) or not present (0). For the regression analyses we used a sum score of the biographical risk factors (possible range 0-17). The five predominant risk factors were low socio-economic status of the parents ( $51 \%$ of the patients), severe physical disease of one parent (37\%), contact with social services (29\%), age difference between siblings less than 18 months $(21 \%)$ and chronic marital problems of parents (19\%).

Antonovsky's Sense of Coherence questionnaire (SOC), ${ }^{31}$ a measure of an individual's resilience to stress and his or her capacity to cope with it, was used in the 29-item full version. Individuals with high SOC scores are supposed to perceive stressors as predictable and explicable, have confidence in their capacity to overcome stressors, and judge it worthwhile to rise to the challenges they face. Test properties such as test-retest reliability and internal consistency of the SOC scale are excellent. ${ }^{32}$ In our study, Cronbach's $\alpha$ was 0.90 .

The Freiburg Questionnaire of Coping with Illness (FQCI) is a validated 35 -item self-rating coping questionnaire comprising five sub-scales: depressive reaction; active, problem-oriented coping; distraction; religiosity and search for meaning; downplaying and wishful thinking. ${ }^{33}$ Internal consistency is $0.63-0.70$ for the active, problem-oriented coping scale used in this study. ${ }^{34}$ For the assessment of anxiety and depression we used the Hospital Anxiety and Depression Scale (HADS), ${ }^{35}$ a 14 -item self-rating questionnaire. This scale was developed to provide clinicians and scientists with a reliable, valid and practical tool for identifying and quantifying the two most common forms of psychological disturbance in medical patients. Internal consistencies of the English and the German versions are within the ranges of 0.80 0.93 for the anxiety sub-scale and $0.81-0.90$ for the depression sub-scale. ${ }^{36}$

The subjective appraisal of the severity of the accident was rated by the patients on a Likert scale ranging from 1 (very slight) to 5 (very severe). For the assessment of the life-threatening nature of the accident, participants were asked whether or not they felt their life was at risk during or after the accident. In the followup assessments, the interviews began with an unstructured part in which patients were asked about any special events in the meantime and their general state of health.

\section{Statistical analysis}

For the prediction of PTSD symptom severity at the 3-year followup, we tested the same linear regression model as described in detail for the 1-year follow-up, using linear multiple regression analysis. ${ }^{37}$ We used the same prediction model to test its longterm stability. Ten potential predictor variables, all assessed at the initial measurement shortly after the accident, were selected based on both 'pathogenic' and 'salutogenic' considerations. ${ }^{31}$ The ISS was chosen as the only objective accident-related variable. Gender was included as a variable because, in general, PTSD is more likely to develop in women than in men after exposure to a traumatic event. ${ }^{38}$ Biographical risk factors and stress due to life events were selected as potential pre-traumatic risk factors. Furthermore, the patients' subjective view was represented in the model by their appraisals of the severity and threat to life of the accident. Early post-traumatic psychopathology was entered in the equation using the IES Intrusion sub-scale; salutogenic aspects were represented by the SOC and the patients' social network. Finally, the FQCI sub-scale 'active, problem-oriented coping' was included because such coping strategies were most frequently used in our sample and because the literature on the adaptivity of active coping strategies is still controversial. ${ }^{39}$ Linear multiple regression analysis was used for the prediction of PTSD symptom severity (CAPS total score) at the 3-year follow-up. Details of the statistical procedure are described in the report of the 1-year follow-up data.

Group comparisons of dimensional variables were performed with one-way analysis of variance (ANOVA) and $t$-tests. Correlations were calculated using Pearson's correlation coefficients. For categorical variables the chi-squared test was used, or Fisher's exact test if the expected count was less than five in more than $20 \%$ of cells.

\section{Ethical approval}

Ethical approval was granted by the institutional review board of the canton of Zurich. Written informed consent was obtained from all participants.

\section{Results}

\section{Sample}

Socio-demographic characteristics of the sample are presented in Table 1. Road traffic accidents were the most frequent cause of injury ( $59 \%$; $n=53)$, followed by sports and leisure-time accidents $(21 \% ; n=19)$, accidents in the workplace $(14 \% ; n=13)$ and 


\begin{tabular}{|c|c|}
\hline \multicolumn{2}{|l|}{ Variable } \\
\hline Age, years: mean (s.d.) & $38.9(13.2$ \\
\hline \multicolumn{2}{|l|}{ Gender, $n(\%)$} \\
\hline Male & $69(77)$ \\
\hline Female & $21(23)$ \\
\hline \multicolumn{2}{|l|}{ Marital status, $n(\%)$} \\
\hline Single & 34 (38) \\
\hline Married & $43(48)$ \\
\hline Divorced & $13(14)$ \\
\hline \multicolumn{2}{|l|}{ Living arrangements, $n(\%)$} \\
\hline Alone & $17(19)$ \\
\hline With others (family, partner, friends) & $73(81)$ \\
\hline \multicolumn{2}{|l|}{ Maximum educational level, $n$ (\%) } \\
\hline No education & $2(2)$ \\
\hline Obligatory school & $12(13)$ \\
\hline Apprenticeship & $49(54)$ \\
\hline College & $4(4)$ \\
\hline Technical or commercial college & $17(19)$ \\
\hline University & $6(7)$ \\
\hline \multicolumn{2}{|l|}{ Employment status, $n$ (\%) } \\
\hline Paid work (full- or part-time) & $80(89)$ \\
\hline No paid work (homemaker, retired, unemployed) & $4(4)$ \\
\hline Student & $6(7)$ \\
\hline
\end{tabular}

household accidents $(6 \% ; n=5)$. No significant difference in injury severity (ISS) was found between these four types of accident ( $F=0.247$, d.f. $=3,86, P=0.86$ ). According to the surgeons' files, 35 patients (39\%) experienced retrograde amnesia; 38 patients (42\%) sustained mild to moderate traumatic brain injury (i.e. they had objectively reported loss of consciousness and/or pathological findings on cranial computed tomography). Comparison between the final study group ( $n=90)$ and the 14 patients who refused to participate did not reveal significant difference with regard to gender, age, ISS or GCS score. Work-related accidents were significantly more frequent among those who refused to participate $(50 \% ; n=7)$ compared with the sample $(14 \% ; n=13)$ (Fisher's exact test, $P<0.01)$. Therefore, in the final sample patients who sustained a work-related accident were compared with the rest. No significant difference with regard to PTSD symptoms was found $\left(T_{1}\right.$ CAPS mean total score 24.5 v. 17.9; $t=-1.46$, d.f. $=88, P=0.15$ ).

There was no significant difference between the 31 patients who withdrew from the study and the 90 patients who participated in all four interviews with regard to socio-demographic and accident-related variables, except for marital status (dropout group: 21 single, 9 married, 1 divorced; participant group: 34 single, 43 married, 13 divorced; $\chi^{2}=8.95$, d.f. $\left.=2, P<0.05\right)$ and subjective appraisal of accident severity (dropout group: 3.9, s.d.=1.0; participant group: 4.3 , s.d. $=0.8 ; t=2.01$, d.f. $=113, P<0.05)$. No difference was found at $T_{1}$ for scores on the following scales: ISS, GCS, CAPS, IES, SCL-90-R, SOC and the FQCI.

\section{Descriptive data}

The main accident-related characteristics of the sample are presented in Table 2. There was no significant correlation between ISS and the patients' subjective appraisals of the event (threat to life: Pearson $r=0.07$; accident severity: Pearson $r=-0.06$, both not significant). Experiencing the accident as life-threatening was reported by 21 patients $(23 \%)$. More detailed information about the surgical and psychosocial assessments has been presented in an earlier publication. ${ }^{37}$

\section{Prevalence of PTSD and sub-threshold disorder}

At baseline $\left(T_{1}\right) 5$ participants $(6 \%)$ met all criteria for PTSD (except for the duration criterion) and 19 (21\%) met criteria for sub-threshold disorder. At 6 months $\left(T_{2}\right) 3$ participants (3\%) were diagnosed with full PTSD and 8 (9\%) with sub-threshold disorder. At 1 year $\left(T_{3}\right) 2$ participants (2\%) were diagnosed with full PTSD and $10(11 \%)$ with sub-threshold disorder. Three years after the accident $\left(T_{4}\right), 4$ participants $(4 \%)$ met the criteria for full PTSD and $9(10 \%)$ for sub-threshold disorder. At some point during follow-up, 32 patients (36\%) met the criteria for either full or sub-threshold PTSD. Changes of diagnoses over time are shown in Fig. 1. The increase from 2 cases of PTSD at 1 year to 4 cases at 3-year follow-up was not significant (McNemar test, exact $P=0.63$, two-tailed).

\section{Severity of PTSD symptoms over time}

The mean CAPS score was 18.9 (s.d.=15.0, range 0-79) at baseline $\left(T_{1}\right), 10.9$ (s.d.=13.4, range $\left.0-57\right)$ at 6 months $\left(T_{2}\right), 13.4$ (s.d.=15.6, range $0-64)$ at 1 year $\left(T_{3}\right)$ and 10.6 (s.d. $=15.2$, range $0-60)$ at 3-year follow up $\left(T_{4}\right)$, indicating a relatively low overall PTSD symptom level in this sample. The CAPS score at $T_{4}$ correlated significantly with CAPS scores at $T_{1}-T_{3}$ (Pearson's correlations: $T_{1} r=0.46 ; T_{2} r=0.82 ; T_{3} r=0.81$; all $P<0.01$ ).

\section{Predictors of PTSD at 3 years}

For the prediction of PTSD symptom severity at the 3-year followup we applied the prediction model we had established for the 1-year follow-up. ${ }^{37}$ For the multiple regression analysis, complete data for 89 participants (1 missing) were available. Our model remained largely stable over time, explaining $32 \%$ of the variance of PTSD symptoms 1 year post-accident and 23\% at 3 years postaccident. Biographical risk factors and the IES Intrusion sub-scale contributed significantly to the prediction, whereas the patients' sense of threat to life and active problem-oriented coping (FQCI) - significant at 1 year - no longer made a significant contribution (Table 3).

\section{Course of PTSD symptom severity over 3 years}

In our search for variations in the natural course of PTSD symptoms, we concentrated on patients with a CAPS score of 30 or

\begin{tabular}{lcc} 
Table 2 Accident-related characteristics of the sample $(n=90)$ & Mean (s.d.) & Minimum \\
Variable & $21.9(10.1)$ & 10 \\
\hline Injury Severity Score & $14.5(1.4)$ & 51 \\
\hline Glasgow Coma Scale score & $5.7(5.1)$ & 15 \\
\hline Length of stay in intensive care unit, days & $33.8(32.9)$ & 1 \\
\hline Length of stay at the University Hospital, days & $73.1(77.3)$ & 26 \\
\hline Length of stay at the University Hospital and rehabilitation, days & $4.3(0.82)$ & 4 \\
\hline Self-appraisal of accident severity & 565 & 220 \\
\hline
\end{tabular}


PTSD

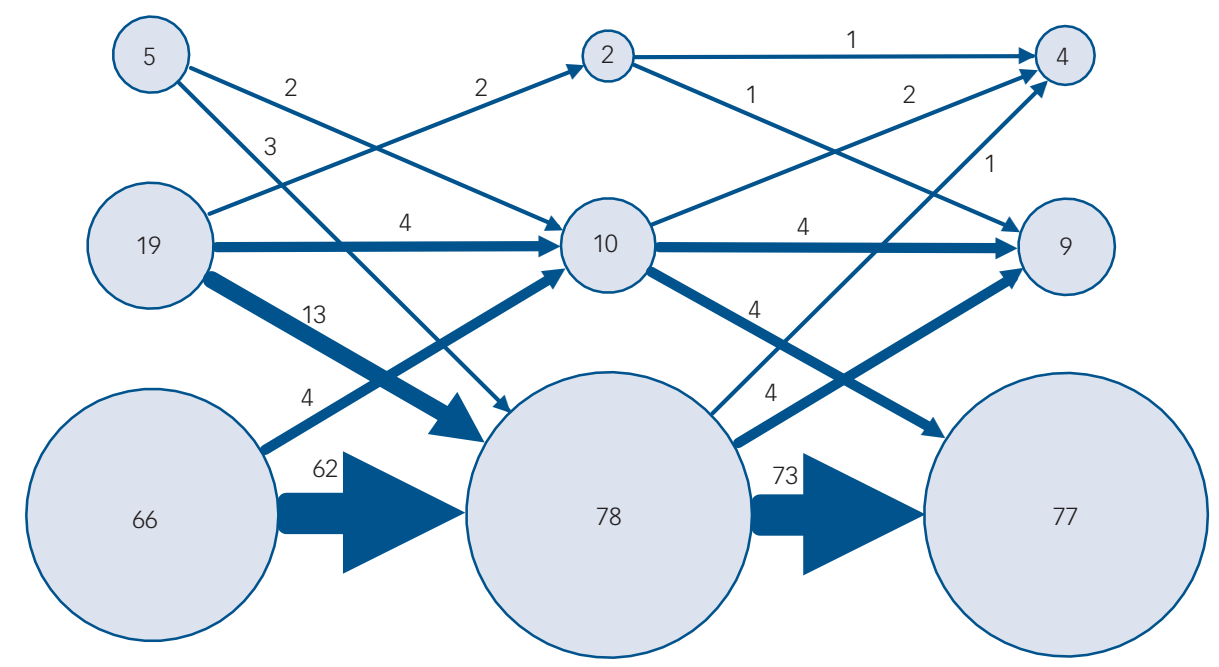

Fig. 1 Changes of diagnoses over a 3-year period after the accident. $T_{1} 2$ weeks, $T_{3} 12$ months, $T_{4} 36$ months post-accident ( $\left.n=90\right)$.

PTSD, post-traumatic stress disorder

a. Time criterion for PTSD not fulfilled.

more at any measurement point $(28 \% ; n=25)$. Using the following procedure we identified three types of PTSD course. Our first step was to separate patients showing an initial increase in PTSD symptoms ('increasing' group, Fig. $2(\mathrm{a}) ; n=10$ ) from patients with an initial decrease of symptoms $(n=15)$ in the first 6 months posttrauma. As a second step we subdivided the group of patients with an initial decrease into a group scoring above 30 on the CAPS at $T_{1}$ only ('decreasing' group, Fig. $2(\mathrm{~b}) ; n=8$ ) and a group of patients with a secondary increase of the CAPS score above 30 later on ('delayed increase' group, Fig. 2(c); $n=7$ ). The course of PTSD symptoms over time for these three groups of patients is shown in Fig. 2.

The three groups of PTSD courses and the remaining less symptomatic group did not differ with regard to age $(F=0.49$, d.f. $=3,86, P=0.69)$ and gender $\left(\chi^{2}=2.08\right.$, d.f. $\left.=3, P=0.56\right)$. Regarding stress due to life events, Scheffé post hoc analyses in one-way ANOVA revealed that the 'increasing' group and the 'delayed increase' group represented a homogeneous subset of means compared with the 'decreasing' group and patients who never scored above 30 on the CAPS. Accordingly, the 'increasing' and 'delayed increase' groups reported significantly more stress due to recent life events at each time point ( $t$-tests, all $P<0.001$; e.g. $t=5.38$, d.f. $=88, P<0.001$ at $T_{2}$ ) than the 'decreasing' group combined with the group who never scored above 30 on the CAPS. In addition, we analysed the narrative part of the follow-up interviews on a qualitative single case level in the 'increasing' group and the 'delayed increase' group. In this unstructured introductory part of the interview, patients were asked informally to talk about important events that happened since the last interview and about any general concerns they might have.

In the 'increasing' group (Fig. 2(a)), seven patients reported persistent physical problems and four reported ongoing litigation or compensation claims. One patient was involved in a motor vehicle accident without injury about 1 year after the index accident and 2 weeks before the $T_{3}$ interview. One patient was diagnosed with a malignant brain tumour 2 years after the accident and was involved in a divorce suit. Another patient reported severe persistent erectile dysfunction as a consequence of the accident. In the 'delayed increase group' (Fig. 2(c)), five patients reported persistent physical problems; another two experienced

Table 3 Multiple regression analysis: prediction of post-traumatic stress disorder symptoms at 1-year and 3-year follow-up

\begin{tabular}{|c|c|c|c|c|}
\hline \multirow[b]{2}{*}{ Predictor variable } & \multicolumn{2}{|c|}{1 year $^{\mathrm{a}}$} & \multicolumn{2}{|c|}{3 years $^{b}$} \\
\hline & Beta & $P$ & Beta & $P$ \\
\hline Injury Severity Score & -0.01 & NS & 0.03 & NS \\
\hline Female gender & 0.12 & NS & 0.17 & NS \\
\hline Number of biographical risk factors & 0.24 & $<0.05$ & 0.24 & $<0.05$ \\
\hline Stress due to life events (past 2 years) & 0.09 & NS & 0.07 & NS \\
\hline Sense of death threat & 0.23 & $<0.05$ & 0.10 & NS \\
\hline Subjective appraisal of accident severity & 0.01 & NS & 0.06 & NS \\
\hline IES Intrusion sub-scale & 0.24 & $<0.05$ & 0.24 & $<0.05$ \\
\hline Sense of Coherence & -0.01 & NS & -0.08 & NS \\
\hline Size of social network & 0.01 & NS & 0.10 & NS \\
\hline Active, problem-oriented coping (FQCI) & 0.21 & $<0.05$ & 0.16 & NS \\
\hline
\end{tabular}


(a) Increasing group $(n=10)$

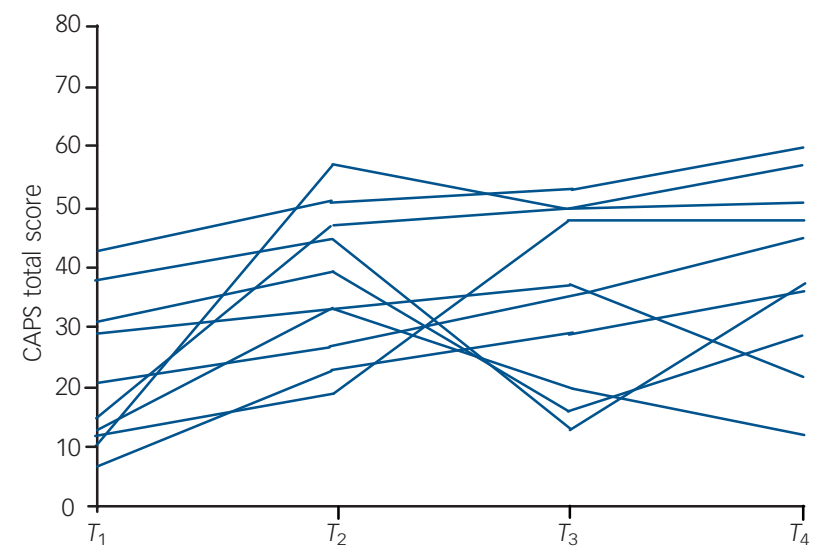

(b) Decreasing group $(n=8)$

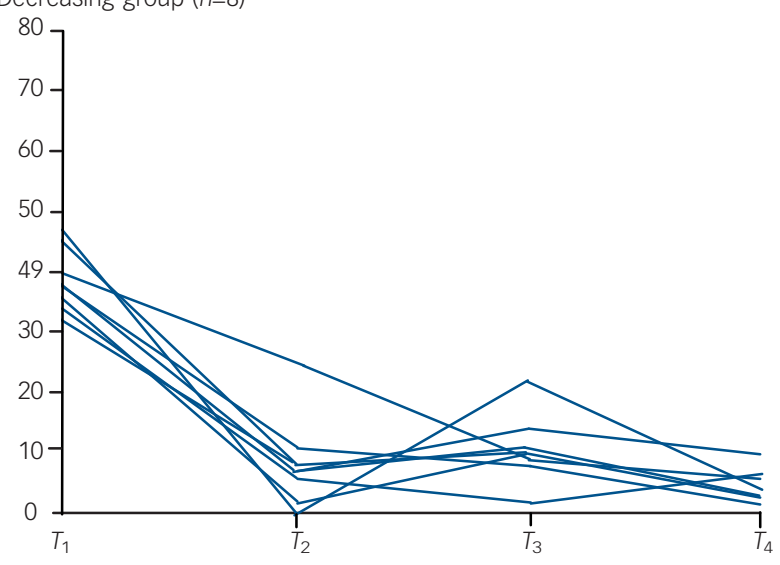

(c) Delayed increasing group $(n=7)$

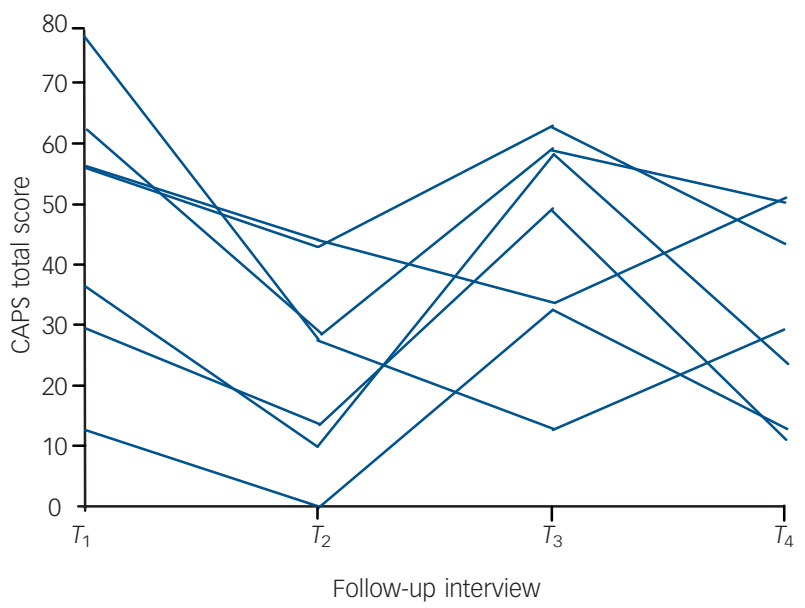

Fig. 2 Course of post-traumatic stress disorder symptoms over time.

CAPS, Clinician-Administered PTSD Scale.

\section{Comorbid anxiety and depression}

At the $T_{3}$ assessment, 84 of the 90 patients (93\%) completed the HADS. Seven patients (8\%) scored above the cut-off level of 7 points for possible depression. Patients diagnosed with full or sub-threshold PTSD at $T_{3}$ were more likely to have scores above the cut-off point for depression (Fisher's exact test, $P<0.01$ ). Fifteen (18\%) patients scored above the cut-off of 7 for possible anxiety disorder. Patients diagnosed with full or sub-threshold PTSD were more likely to have scores above the cut-off for anxiety (Fisher's exact test, $P<0.001$ ). At $T_{3}$ the CAPS scores correlated significantly with the HADS depression (Pearson $r=0.61$, $P<0.001$ ) and HADS anxiety (Pearson $r=0.71, P<0.001$ ) subscale scores at the same assessment.

Complete HADS data were available for 87 patients (97\%) at $T_{4}$. Nine patients (10\%) scored above the cut-off level for possible depression. Again, patients diagnosed with full or sub-threshold PTSD at $T_{4}$ were more likely to be above the cut-off for depression (Fisher's exact test, $P<0.001)$. Seventeen $(19 \%)$ patients were above the cut-off for possible anxiety disorder. Patients diagnosed with full or sub-threshold PTSD were more likely to score above the cut-off point for anxiety (Fisher's exact test, $P<0.001$ ). At $T_{4}$ again there was a significant correlation between CAPS scores and HADS depression (Pearson $r=0.77, P<0.001$ ) and HADS anxiety (Pearson $r=0.80, P<0.001$ ) sub-scale scores.

\section{Psychological or psychopharmacological treatment}

At $T_{4}$, six patients (7\%) reported psychopharmacological and/or psychotherapeutic treatment related to the accident (psychotherapy and psychopharmacological treatment, $n=2$; psychopharmacological treatment only, $n=3$; psychotherapy only, $n=1$ ). Of these, four were diagnosed with PTSD or sub-threshold PTSD at any assessment point.

\section{Discussion}

There has been an increasing awareness of the risk of psychological reactions in the aftermath of accidents and physical injuries. ${ }^{40}$ Several studies have investigated psychiatric morbidity following accidental injury. ${ }^{8-11,41}$ Post-traumatic stress symptoms tend to decrease within the first months after a trauma but from epidemiological studies we know that if such symptoms persist beyond 3-6 months they are likely to become chronic. ${ }^{12,42-44}$ Therefore, prospective long-term studies are important for the improvement of the understanding of the course of PTSD and for the identification of factors leading to chronicity. A few prospective long-term studies of accident survivors have been published previously. ${ }^{13-15,45}$ Harvey \& Bryant published a 2-year follow-up study following mild traumatic brain injury. ${ }^{45}$ However, our study is the first prospective longitudinal investigation over a 3-year follow-up period, looking into PTSD in severely injured survivors of mostly life-threatening accidents using a structured diagnostic interview.

\section{Prevalence of full and sub-threshold PTSD}

In our study the prevalence of PTSD was low over the whole period of 3 years $(2-6 \%)$. In other follow-up studies PTSD rates in the first year after physical injury range from $10 \%$ to $39 \% .^{8,10,46,47}$ Despite the clinical and public health importance of long-term follow-up data, until now only a few studies have provided long-term data. Malt investigated the psychiatric consequences of accidental injuries with a mean period of follow-up of 28 months (range 16-51) and found only one case of PTSD in 107 
patients. ${ }^{13}$ This has to be qualified, however, because at the time of Malt's study no structured interview for PTSD was available. Rates of PTSD from $8 \%$ following road traffic accidents were found by Mayou et al in a 5-year follow-up, ${ }^{14}$ and $11 \%$ in another large prospective study at 3 years. ${ }^{15,48}$ The low PTSD prevalence found in our study is remarkable, particularly considering the severity of the injuries sustained by the participants. In all other reported studies the patients were far less physically injured. With regard to socio-demographic characteristics, Malt's sample was comparable with ours, and patients with severe mental and physical handicap before the injury were also excluded. By restricting the sample to participants with no pre-existing severe psychiatric problem, patients at higher risk of developing PTSD might have been excluded. However, in a replication study we included patients with pre-existing psychiatric disorders but failed to find higher PTSD rates. ${ }^{49}$ Another explanation for the lower PTSD rate in our sample, as well as in Malt's study, ${ }^{13}$ might be the use of clinically experienced interviewers, whereas in other studies self-report questionnaires were used. ${ }^{14,50}$ In a clinical interview it is certainly easier to differentiate accurately between normal reactions and psychopathological symptoms, whereas in selfreport questionnaires this could lead to an overestimation of PTSD.

Although the prevalence of full PTSD was low in our study, it is remarkable that at some point during follow-up 32 patients $(36 \%)$ met the criteria for either full or sub-threshold disorder. This concurs with Malt, who reported that approximately a third of patients who despite experiencing definite fear associated with exposure to situations that symbolised the traumatic event or exhibiting avoidance behaviour or symptoms of hyperarousal, did not qualify for a diagnosis of PTSD. ${ }^{13}$ These findings are important because there is evidence that the level of impairment in social and work functioning in people with sub-threshold PTSD is comparable with that in people with the full disorder. ${ }^{16}$ For clinical purposes DSM-IV criteria - especially criterion C (avoidance) - may be too restrictive. ${ }^{51}$

A possible explanation for the relatively low rate of experienced death threat could be that 35 patients (39\%) suffered from retrograde amnesia. Dissociative amnesia is one of the symptoms of PTSD, but in accidental injury it is not always possible to establish whether amnesia is due to organic or psychogenic reasons. One could argue that amnesia due to mild traumatic brain injury might protect against the development of PTSD, but Harvey \& Bryant showed that PTSD can occur even if patients report amnesia for the traumatic event due to mild traumatic brain injury, ${ }^{45,52}$ and the stay on an intensive care unit itself can be experienced as traumatic.

The low incidence of PTSD is in line with recent findings of PTSD in an epidemiological study from Switzerland, ${ }^{53}$ where the prevalence of exposure to potentially traumatic events in the general population was relatively low compared with other epidemiological studies. ${ }^{54,55}$ Surprisingly, there was not a single case of full PTSD in the sample, and the prevalence of even sub-threshold PTSD was very low. The fact that Switzerland has not been involved in a war for well over a century, has not experienced any major natural disasters in recent decades and enjoys a relatively low crime rate and virtual absence of terrorism, in addition to its political and economic stability, may well contribute to a sense of security which to some extent might protect Swiss citizens from developing PTSD in the aftermath of traumatic experiences. ${ }^{53}$ As low PTSD rates have also been found across several populations at risk in Switzerland when using different assessment instruments, it is likely that the prevalence of PTSD in Switzerland is very low compared with international data and that it is not a methodological bias. ${ }^{49,56,57}$

\section{Predictors of PTSD at 3 years}

The prediction model we used at 1 year explained $32 \%$ of the variance in PTSD symptom severity and was, as expected, less predictive 3 years after the initial trauma, but still explained $23 \%$ of the variance, underlining the remarkable stability of the model. It is worth noting that the severity of the injury did not contribute to the long-term prediction of PTSD, whereas intrusive symptoms shortly after the accident and biographical risk factors turned out to be robust predictors of later PTSD symptom level.

\section{Course of PTSD over 3 years}

The course of PTSD after disaster has been studied in relatively few studies. ${ }^{44}$ In our sample there were notable changes on a categorical level between PTSD, sub-threshold PTSD and no PTSD cases over time in different directions (Fig. 1). This is in line with other long-term studies, ${ }^{14,50,58}$ and with studies with more than two assessment points. ${ }^{46}$ There was a slight increase in PTSD cases from 2 cases at 1 year to 4 cases at 3 -year follow-up. This is in accordance with findings from long-term studies on the course of PTSD among survivors of disasters. ${ }^{44}$ Our findings underline the importance of looking not only at prevalence rates but also at the individual patient's clinical course. Although the majority of participants (72\%) never had a CAPS score above 30, we identified three different types of courses of PTSD symptoms in those scoring above 30 at any assessment point (Fig. 2). The 'decreasing' group appeared to be the least problematic group, which is in line with our clinical experience that some patients after sustaining an accident temporarily experience acute stress symptoms that spontaneously resolve without further intervention. The 'increasing' group and the 'delayed increase' group are of special clinical interest. Our results support the hypothesis that patients who still reported PTSD symptoms at 6 months would rarely spontaneously recover in the further course, and that a proportion of those who newly developed symptoms after an initial latency would remain symptomatic in the long term. It is all the more remarkable that few participants reported psychological and/or psychopharmacological treatment. As only 6 participants underwent such treatment in our study, further analyses on this subject were not possible. Analyses of the narrative part of the interview showed that individual factors indirectly associated with the accident, such as somatic complications, physical pain, litigation and compensation claims, might have an important role in the rehabilitation process, and so have an impact on PTSD symptom levels too.

\section{Comorbid anxiety and depression}

Although PTSD is a specific reaction to traumatic events, anxiety and depression also occur frequently after trauma. ${ }^{8,59}$ Moreover, the high psychiatric comorbidity in people with PTSD is a wellknown phenomenon: anxiety and affective disorders are especially associated with this disorder. ${ }^{12,55}$ Although pre-existing psychiatric disorder was an exclusion criterion for this study, almost $10 \%$ of the participants without a PTSD diagnosis scored above the cut-off level for an anxiety disorder. By focusing only on PTSD, one might overlook the non-specific psychiatric conditions related to the accident.

\section{Strengths and limitations of the study}

One of the strengths of our study is that we collected a homogeneous, consecutive sample of cases of severe accidental injury without major brain damage, confirmed by a mean ISS of 21.9 and a mean GCS score of 14.5. Furthermore, all interviews were 
conducted by clinically experienced medical doctors, using identical and well-validated instruments at all four assessment points. Also, patient recruitment was unlikely to have led to bias. Of 135 patients originally eligible for inclusion, 121 were recruited at baseline (90\%) and of these, 90 (74\%) completed all four assessments.

Several limitations have to be addressed. The restriction of the sample for practical reasons to German-speaking patients has been discussed as a potential source of bias. ${ }^{37}$ By excluding participants who did not speak the local language sufficiently and who might therefore experience less integration and social support, we could have missed a group of patients with a higher risk of developing PTSD, ${ }^{38,60}$ and this might have led to our finding a lower prevalence of the disorder. However, this was not supported by our replication study, where we included non-German-speaking patients. ${ }^{49}$ With regard to the DSM-IV stressor criterion, all patients fulfilled stressor criterion A1 (exposure to a potentially traumatic event), but with only one in four patients experiencing a sense of threat to life during the accident, despite the severity of their injuries, stressor criterion A2 (subjective reaction involving intense fear, helplessness or horror) probably was not met by all participants. The low level of symptoms of post-traumatic stress in our sample might limit the prediction model to be carried forward to populations of trauma victims with higher PTSD rates. Further, the explained variance in PTSD symptom severity of $32 \%$ at 1 year and $23 \%$ at 3 years reduces the clinical relevance of the prediction model.

The grouping of biographical risk factors using a range of $0-17$ can be seen as a further limitation: the underlying assumption that the higher the total number of factors the higher the risk does not fully account for the different impact these risk factors might have. Childhood sexual abuse, for example, is a particularly strong predictor of PTSD in adulthood. However, in the interest of comparability with our regression model predicting PTSD symptom levels at 1 -year follow-up, ${ }^{37}$ we decided to use the same construct for the 3-year follow-up. The biographical risk factors assessed in this study were general psychosocial risk factors in childhood predicting psychological health in the long term, not specifically the development of PTSD. Meanwhile, specific risk factors for PTSD are well-established, ${ }^{38,60}$ and for further studies it will be of interest to assess these factors.

\section{Clinical implications}

Only a few patients in our study fulfilled the criteria for full PTSD. However, about a third of all patients met the criteria for either full or sub-threshold PTSD at some point in time. For clinical practice it is important to identify patients who still report symptoms 6 months after their accident or develop delayed symptoms. Such patients are most probably in need of further psychological assessment and psychotherapeutic treatment.

\footnotetext{
Urs Hepp, MD, Psychiatrische Dienste Aargau AG, Baden, and Department of Psychiatry, University Hospital Zurich, Switzerland; Hanspeter Moergeli, PhD, Stefan Buchi, MD, Department of Psychiatry, University Hospital Zurich, Switzerland Helke Bruchhaus-Steinert, MD, Institute for Ecological Systemic Therapy, Zurich, Helke Bruchhaus-Steinert, MD, Institute for Ecological Systemic Therapy, Zurich,
Switzerland; Bernd Kraemer, MD, Department of Psychiatry, University Hospital Zurich, Switzerland; Tom Sensky, FRCPsych, Division of Neurosciences and Psychological Medicine, Imperial College School of Medicine, London, UK; Ulrich Schnyder, MD, Department of Psychiatry, University Hospital Zurich, Switzerland
}

Correspondence: Dr Urs Hepp, Psychiatrische Dienste Aargau AG, Haselstrasse 1, CH-5401 Baden, Switzerland. Email: Urs.Hepp@pdag.ch

First received 3 Sep 2007, final revision 18 Dec 2007, accepted 7 Feb 2008

\section{Acknowledgements}

This study was supported by the Swiss National Science Foundation (project no. 3243640.95, 32-053736.98). The authors wish to thank Christel Nigg for collecting a substantial part of the data reported on in this paper. Claus Buddeberg, Otmar Trentz and Jürg Willi provided support in designing the study.

\section{References}

1 American Psychiatric Association. Diagnostic and Statistical Manual of Mental Disorders (3rd edn) (DSM-III). APA, 1980.

2 Breslau N, Davis GC. Posttraumatic stress disorder: the etiologic specificity of wartime stressors. Am J Psychiatry 1987; 144: 578-83.

3 Lee KA, Vaillant GE, Torrey WC, Elder GH. A 50-year prospective study of the psychological sequelae of World War II combat. Am J Psychiatry 1995; 152: 516-22.

4 Shore JH, Vollmer WM, Tatum EL. Community patterns of posttraumatic stress disorders. J Nerv Ment Dis 1989; 177: 681-5.

5 Bisson JI, Shepherd JP. Psychological reactions of victims of violent crime. Br J Psychiatry 1995; 167: 718-20.

6 Bownes IT, O'Gorman EC, Sayers A. Assault characteristics and posttraumatic stress disorder in rape victims. Acta Psychiatr Scand 1991; 83: 27-30.

7 American Psychiatric Association. Diagnostic and Statistical Manual of Mental Disorders (4th edn) (DSM-IV). APA, 1994.

8 Blanchard EB, Hickling EJ, Taylor AE, Loos W. Psychiatric morbidity associated with motor vehicle accidents. J Nerv Ment Dis 1995; 183 495-504.

9 Fuglsang AK, Moergeli H, Hepp-Beg S, Schnyder U. Who develops acute stress disorder after accidental injuries? Psychother Psychosom 2002; 71: 214-22.

10 Koren D, Arnon I, Klein E. Acute stress response and posttraumatic stress disorder in traffic accident victims: a one-year prospective, follow-up study. Am J Psychiatry 1999; 156: 367-73.

11 Shalev AY, Freedman S, Peri T, Brandes D, Sahar T, Orr SP, Pitman RK. Prospective study of posttraumatic stress disorder and depression following trauma. Am J Psychiatry 1998; 155: 630-7.

12 Kessler RC, Sonnega A, Bromet E, Hughes M, Nelson CB. Posttraumatic stress disorder in the National Comorbidity Survey. Arch Gen Psychiatry 1995; 52: 1048-60.

13 Malt $\mathrm{U}$. The long-term psychiatric consequences of accidental injury. A longitudinal study of 107 adults. Br J Psychiatry 1988; 153: 810-18.

14 Mayou R, Tyndel S, Bryant B. Long-term outcome of motor vehicle accident injury. Psychosom Med 1997; 59: 578-84.

15 Mayou RA, Ehlers A, Bryant B. Posttraumatic stress disorder after motor vehicle accidents: 3-year follow-up of a prospective longitudinal study. Behav Res Ther 2002; 40: 665-75.

16 Zlotnick C, Franklin CL, Zimmerman M. Does 'subthreshold' posttraumatic stress disorder have any clinical relevance? Compr Psychiatry 2002; 43: 413-9.

17 Horowitz M, Wilner N, Alvarez W. Impact of Event Scale: a measure of subjective stress. Psychosom Med 1979; 41: 209-18.

18 Blake DD, Weathers FW, Nagy LM, Kaloupek DG, Klauminzer G, Charney DS, Keane TM. A clinical rating scale for assessing current and lifetime PTSD: the CAPS-1. Behav Ther 1990; 8: 187-8.

19 Baker SP, O'Neill B. The injury severity score: an update. J Trauma 1976; 16: 882-5.

20 Teasdale G, Jennett B. Assessment of coma and impaired consciousness. A practical scale. Lancet 1974; 2: 81-4.

21 American Psychiatric Association. Diagnostic and Statistical Manual of Mental Disorders (3rd edn, revised) (DSM-III-R). APA, 1987.

22 Stein MB, Walker JR, Hazen AL, Forde DR. Full and partial posttraumatic stress disorder: findings from a community survey. Am J Psychiatry 1997; 154: 1114-9.

23 Blake DD, Weathers FW, Nagy LM, Kaloupek DG, Gusman FD, Charney DS, Keane TM. The development of a Clinician-Administered PTSD Scale. J Trauma Stress 1995; 8: 75-90.

24 Schnyder $\mathrm{U}$, Moergeli $\mathrm{H}$. German version of Clinician-Administered PTSD Scale. J Trauma Stress 2002; 15: 487-92.

25 Derogatis LR. SCL-90-R: Administration, Scoring and Procedure Manual-II for the Revised Version. Clinical Psychometric Research, 1986.

26 Franke G. SCL-90-R. Die Symptomcheckliste von Derogatis - Deutsche Version - Manual. Beltz, 1995. 
27 Berkman LF, Syme SL. Social networks, host resistance, and mortality: a nine-year follow-up study of Alameda County residents. Am J Epidemiol 1979; 109: 186-204.

28 Schaefer C, Coyne JC, Lazarus RS. The health-related functions of social support. J Behav Med 1981; 4: 381-406.

29 Siegrist J, Dittmann KH. Inventar zur Erfassung lebensverändernde Ereignisse (ILE). In ZUMA - Handbuch sozialwissenschaftlicher Skalen. Informationszentrum Sozialwissenschaften, 1983 [Inventory for determining life-changing events (ILE). In ZUMA - Handbook of Social Science Scales. Information Centre of Social Sciences, 1983].

30 Egle UT, Hoffmann SO, Steffens M. Psychosocial risk and protective factors in childhood and adolescence as predisposition for psychiatric disorders in adulthood. Current status of research [in German]. Nervenarzt 1997; 68: 683-95.

31 Antonovsky A. Unraveling the Mystery of Health: How People Manage Stress and Stay Well. Jossey-Bass, 1987.

32 Antonovsky A. The structure and properties of the sense of coherence scale. Soc Sci Med 1993; 36: 725-33.

33 Muthny FA. Freiburger Fragebogen zur Krankheitsverarbeitung: Manual. Beltz, 1989 [The Freiburg Questionnaire of Coping with Illness Manual].

34 Hardt J, Petrak F, Egle UT, Kappis B, Schulz G, Küstner E. Was misst der FKV? Eine Überprüfung des Freiburger Fragebogens zur Krankheitsverarbeitung bei Patienten mit unterschiedlichen Erkrankungen [What does the Freiburg Questionnaire of Coping with Illness measure? Evaluation of the Freiburg Questionnaire of Coping with Illness in patients with different diseases]. Z Klin Psychol Psychother 2003; 32: 41-50.

35 Zigmond AS, Snaith RP. The hospital anxiety and depression scale. Acta Psychiatr Scand 1983; 67: 361-70.

36 Herrmann C. International experiences with the Hospital Anxiety and Depression Scale - a review of validation data and clinical results. J Psychosom Res 1997; 42: 17-41.

37 Schnyder $\mathrm{U}$, Moergeli $\mathrm{H}$, Klaghofer $\mathrm{R}$, Buddeberg $\mathrm{C}$. Incidence and prediction of posttraumatic stress disorder symptoms in severely injured accident victims. Am J Psychiatry 2001; 158: 594-9.

38 Brewin CR, Andrews B, Valentine JD. Meta-analysis of risk factors for posttraumatic stress disorder in trauma-exposed adults. J Consult Clin Psychol 2000; 68: 748-66.

39 Hepp U, Moergeli H, Buchi S, Wittmann L, Schnyder U. Coping with serious accidental injury: a one-year follow-up study. Psychother Psychosom 2005; 74: $379-86$.

40 O'Donnell ML, Creamer M, Bryant RA, Schnyder U, Shalev A. Posttraumatic disorders following injury: an empirical and methodological review. Clin Psychol Rev 2003; 23: 587-603.

41 Frommberger UH, Stieglitz RD, Nyberg E, Schlickewei W, Kuner E, Berger M. Prediction of posttraumatic stress disorder by immediate reactions to trauma: a prospective study in road traffic accident victims. Eur Arch Psychiatry Clin Neurosci 1998; 248: 316-21.

42 Helzer JE, Robins LN, McEvoy L. Post-traumatic stress disorder in the general population. Findings of the epidemiologic catchment area survey. $N$ Engl J Med 1987; 317: 1630-4.

43 Davidson JR, Hughes D, Blazer DG, George LK. Post-traumatic stress disorder in the community: an epidemiological study. Psychol Med 1991; 21: 713-21.
44 Galea S, Nandi A, Vlahov D. The epidemiology of post-traumatic stress disorder after disasters. Epidemiol Rev 2005; 27: 78-91.

45 Harvey AG, Bryant RA. Two-year prospective evaluation of the relationship between acute stress disorder and posttraumatic stress disorder following mild traumatic brain injury. Am J Psychiatry 2000; 157: 626-8.

46 O'Donnell ML, Creamer M, Pattison P. Posttraumatic stress disorder and depression following trauma: understanding comorbidity. Am J Psychiatry 2004; 161: 1390-6.

47 Ursano RJ, Fullerton CS, Epstein RS, Crowley B, Kao TC, Vance K, Craig KJ Dougall AL, Baum A. Acute and chronic posttraumatic stress disorder in motor vehicle accident victims. Am J Psychiatry 1999; 156: 589-95.

48 Ehlers A, Mayou RA, Bryant B. Psychological predictors of chronic posttraumatic stress disorder after motor vehicle accidents. J Abnorm Psychol 1998; 107: 508-19.

49 Schnyder U, Wittmann L, Friedrich-Perez J, Hepp U, Moergeli H. PTSD following accidental injury: rule or exception in Switzerland? Psychother Psychosom 2008; 77: 111-8

50 Mayou R, Bryant B. Outcome 3 years after a road traffic accident. Psychol Med 2002; 32: 671-5.

51 Schutzwohl M, Maercker A. Effects of varying diagnostic criteria for posttraumatic stress disorder are endorsing the concept of partial PTSD. J Trauma Stress 1999; 12: 155-65.

52 Bryant RA, Harvey AG. Relationship between acute stress disorder and posttraumatic stress disorder following mild traumatic brain injury. Am J Psychiatry 1998; 155: 625-9.

53 Hepp U, Gamma A, Milos G, Eich D, Ajdacic-Gross V, Rossler W, Angst J Schnyder U. Prevalence of exposure to potentially traumatic events and PTSD: the Zurich Cohort Study. Eur Arch Psychiatry Clin Neurosci 2006; 256 $151-8$

54 Kessler RC, Berglund PA, Bruce ML, Koch JR, Laska EM, Leaf PJ Manderscheid RW, Rosenheck RA, Walters EE, Wang PS. The prevalence and correlates of untreated serious mental illness. Health Serv Res 2001; 36 987-1007.

55 Breslau N, Davis GC, Andreski P, Peterson E. Traumatic events and posttraumatic stress disorder in an urban population of young adults. Arch Gen Psychiatry 1991; 48: 216-22.

56 Sommer I, Ehlert U. Adjustment to trauma exposure: prevalence and predictors of posttraumatic stress disorder symptoms in mountain guides. J Psychosom Res 2004; 57: 329-35.

57 Hepp U, Spindler A, Schnyder U, Kraemer B, Milos G. Post-traumatic stress disorder in women with eating disorders. Eat Weight Disord 2007; 12: e24-7.

58 North CS, McCutcheon V, Spitznagel EL, Smith EM. Three-year follow-up of survivors of a mass shooting episode. J Urban Health 2002; 79: 383-91.

59 Malt UF, Olafsen OM. Psychological appraisal and emotional response to physical injury: a clinical, phenomenological study of 109 adults. Psychiatr Med 1992; 10: 117-34.

60 Ozer EJ, Best SR, Lipsey TL, Weiss DS. Predictors of posttraumatic stress disorder and symptoms in adults: a meta-analysis. Psychol Bull 2003; 129 $52-73$. 